\title{
Investigating the Influence of the Pulsed Corona Discharge Over Hypersaline Water
}

\author{
C. Alves-Junior ${ }^{a, b *}$ (D, F.E. Rodrigues-Junior ${ }^{a}$, J.O. Vitoriano ${ }^{b}$, J.B.F.O. Barauna ${ }^{c}$ \\ ${ }^{a}$ Universidade Federal Rural do Semiárido, Departamento de Ciências Exatas e Naturais, Laboratorio \\ de Plasma Aplicação na Agricultura, Saúde e Meio Ambiente - Labplasma, 59625-900, Mossoró, RN, \\ Brasil. \\ ${ }^{b}$ Universidade Federal do Rio Grande do Norte, Programa de pós-graduação em engenharia mecânica, \\ Natal, RN, Brasil. \\ ${ }^{c}$ Biochemistry and Catalysis University of Bucharest, Department of Organic Chemistry, Faculty of \\ Chemistry, 030018, Bucharest, Romania.
}

Received: May 31, 2021; Revised: August 06, 2021; Accepted: August 25, 2021

\begin{abstract}
Desalination plant and saltwork production currently produce large quantities of by-product, in the form of bitterns, which is generally regarded as waste. Up to now methods to discard this waste are unsustainable and restricted by high capital costs and non-universal application. Cold atmospheric plasma over liquids has led to various established industrial implementations, as well as promising applications, including chemical analysis, nanomaterials synthesis and plasma medicine. In this study interaction plasma - hypersaline water using cathodic or anodic polarization was investigated. Pulses of $2.3 \mathrm{kV}$, repeated at a frequency of $1 \mathrm{kHz}$, were applied to produce a pulsed corona discharge (PCD) over hypersaline water (HSW) surface. It was observed that in cathode polarization, considerable number of metallic cations can be extracted from the solution in the form of precipitate salts, while in anodic configuration, despite having a higher spectral intensity for $\mathrm{Na}(589.5 \mathrm{~nm})$, it was less efficient in the salt precipitation. The findings of this study suggest that changing polarization also changes the mechanism of plasma interaction, indicating to be an interesting technique to explore selective saline water chemical extraction.
\end{abstract}

Keywords: Desalination, plasma in liquid, crystallization, hypersaline solutions, separation.

\section{Introduction}

The processes of sea-salt production or during membrane water desalination, currently produce large quantities of by-product, in the form of bitterns. Those bitterns have high concentration of many ions such as $\mathrm{Mg}^{2+}, \mathrm{Cl}^{-}, \mathrm{SO}^{4-}, \mathrm{K}^{+}$ and $\mathrm{Na}^{+}$, which then make it difficult to extract relatively pure salts by evaporation, so it is usually treated as waste ${ }^{1}$. A considerable amount of literature has been published related to the recovery of chemicals from seawater bittern have been predominantly in the development of conventional processes of evaporation-crystallization, ion exchange, and solvent extraction, and these have been widely reviewed in the literature $^{2-7}$. However, any liquid-liquid extraction technique generates organic waste which requires disposal and in some cases the need for solvent regeneration ${ }^{8}$. Among the mineral extraction commercial from seawater without organic waste, the electrolytic processes are more economic ${ }^{9}$. Recently there has been keen interest in the physics and chemistry occurring in electrical discharges through liquids and plasmas formed in saline environments ${ }^{10-13}$. Cold atmospheric plasma (CAP) over liquids has led to various established industrial implementations, as well as promising applications, including chemical analysis, nanomaterials synthesis, plasma medicine and water desalination ${ }^{14-17}$. This wide applications range is possible because interactions between plasmas and liquids

*e-mail: clodomiro.jr@hotmail.com promote many physical and chemical effects as: strong electric fields, mass transfer, changes in $\mathrm{pH}$, generation of reactive species, electron bombardment, etc. These effects can alter crystallization in a different way, depending on the liquid and target compound to be crystallized. For example, electric fields by themselves are studied for its effects in crystallization, because they can change the chemical potential difference between liquid and solid counterparts of a certain compound altering the thermodynamic equilibrium, which may favor crystallization $^{18}$. Conducting liquids, or aqueous solutions containing high number of ions, such as hypersaline water (HSW), are especially interesting for this kind of interaction because they can respond to electric fields much more strongly than non-conducting liquids. Unlike solid electrodes and insulators, conducting liquids can flow in response to electrical and thermal fields, and they can also dissipate energy much more effectively than their non-conducting counterparts, so they may form dynamical structures that open up a range of applications, including plasma-based electrosurgical devices ${ }^{8,19}$ and chemical remediation ${ }^{20}$.

There are essentially two ways of establishing contact between plasma phase and the electrolyte when using one electrode above solution and one immersed. When the negatively charged electrode is separated from the liquid by a gas-phase, the discharge is called cathode discharge, when the negatively charged electrode is immersed, it is called 
anode discharge $\mathrm{e}^{15,21-25}$. There are considerable differences between those systems, physically and chemically, since in the first, electrons are showering from plasma to electrolyte and positive ions are not expected to sputter the surface of the liquid. This configuration is used when reduction is expected in the solution. In the case of expected oxidation, removal of harmful compounds from water, for example, the anodic configuration is preferred because it can create and deliver more oxidative species towards the plasma-liquid interface. In the case of HSW, the expected results should differ for each configuration, but even considering the great amount of literature about plasma-liquid interaction that has already been published ${ }^{12,17,26-29}$ very little is currently known about interaction plasma - HSW. Therefore, in the present study, we use plasma produced by PCD over HSW surface, in helium atmosphere, to evaluate its extracting and/or separating capacity of salts from HSW.

\section{Experimental}

\section{1. $H S W$ samples preparation and plasma treatment}

A sample of HSW was prepared simulating the production in saltworks, that is, sea water was evaporated, and precipitated salts were filtered to obtain a concentrated solution with a density of $1.25 \mathrm{~g} / \mathrm{cm}^{3}$ (Table 1). The concentrations of sodium, calcium and potassium ions were determined by flame spectrophotometry in a flame photometer model

Table 1. Mass concentration of ions in the HSW samples before treatment.

\begin{tabular}{cccccc}
\hline \multicolumn{6}{c}{ Mass concentration $\left(\mathrm{mgL}^{-1}\right)$} \\
\hline $\mathrm{Mg}^{2+}$ & $\mathrm{Ca}^{2+}$ & $\mathrm{Na}^{+}$ & $\mathrm{K}^{+}$ & $\mathrm{Cl}^{-}$ & $\mathrm{SO}_{4}^{2-}$ \\
\hline 58,3 & 0.0 & 82.8 & 24.0 & 239.8 & 27.3 \\
\hline
\end{tabular}

DM-62. Concentration of sulfate ions was analyzed by optical absorption spectroscopy, turbidimetric method, in Spectrophotometer UV-VIS model Genesys 10S, range 410 to $420 \mathrm{~nm}$.

Chlorine and magnesium ions were determined by the Mohr method and complexometric titration, respectively. The titrant on chlorine determination, silver nitrate, was $0,01 \mathrm{M}$ to salt flower samples and $0,1 \mathrm{M}$ to mother solution samples. Magnesium ions was determined by difference between water hardness and calcium concentration. The titrant, EDTA solution, was $0,001 \mathrm{M}$ and $0,1 \mathrm{M}$ to salt flower and solution mother samples, respectively ${ }^{30}$. An experimental apparatus as illustrated (Figure1B) was used for plasma treatment. A reactor ( $40 \mathrm{~mm}$ x $40 \mathrm{~mm}$ x $65 \mathrm{~mm}$ ) hermetically closed, containing $4.20 \mathrm{ml}$ of HSW solution was filled with helium atmosphere established at a flow rate of $100 \mathrm{~cm}^{3} / \mathrm{min}$ carrying species produced in the gas phase into a bubbler. A stainless-steel electrode with radius of $1.0 \mathrm{~mm}$ is placed $5.0 \mathrm{~mm}$ above the reactor filled with HSW (Figure 1C). The plasma was ignited by applying a pulsed voltage negative or positive with width and intensity fixed at $50 \mu$ s and $2.3 \mathrm{kV}$, respectively, repeated at each $1000 \mu \mathrm{s}$, in the working electrode (cathode or anode plasma) over the grounded HSW surface, at a temperature of $25{ }^{\circ} \mathrm{C}$ (Figure 1A). The plasma-liquid interaction lasted $30 \mathrm{~min}$.

The temperature inside the reactor was monitored during the process, where the increase did not exceed $5^{\circ} \mathrm{C}$. This is because in cold atmospheric plasma, due to the small pulse width $(50 \mu \mathrm{s})$ and long repetition time $(1000 \mu \mathrm{s})$, there is not enough time to energy equipartition with the surroundings. A control test, without plasma application, was carried out with a duration of $60 \mathrm{~min}$, to ensure that no precipitation of salts would occur during this period. To analyze the plasma species, an optical fiber was introduced into the plasma-liquid interaction region, $10 \mathrm{~mm}$ away from the discharge, to capture the spectrum and transmit to an optical emission spectrometer (OES) USB 4000, Ocean optics,

(A)
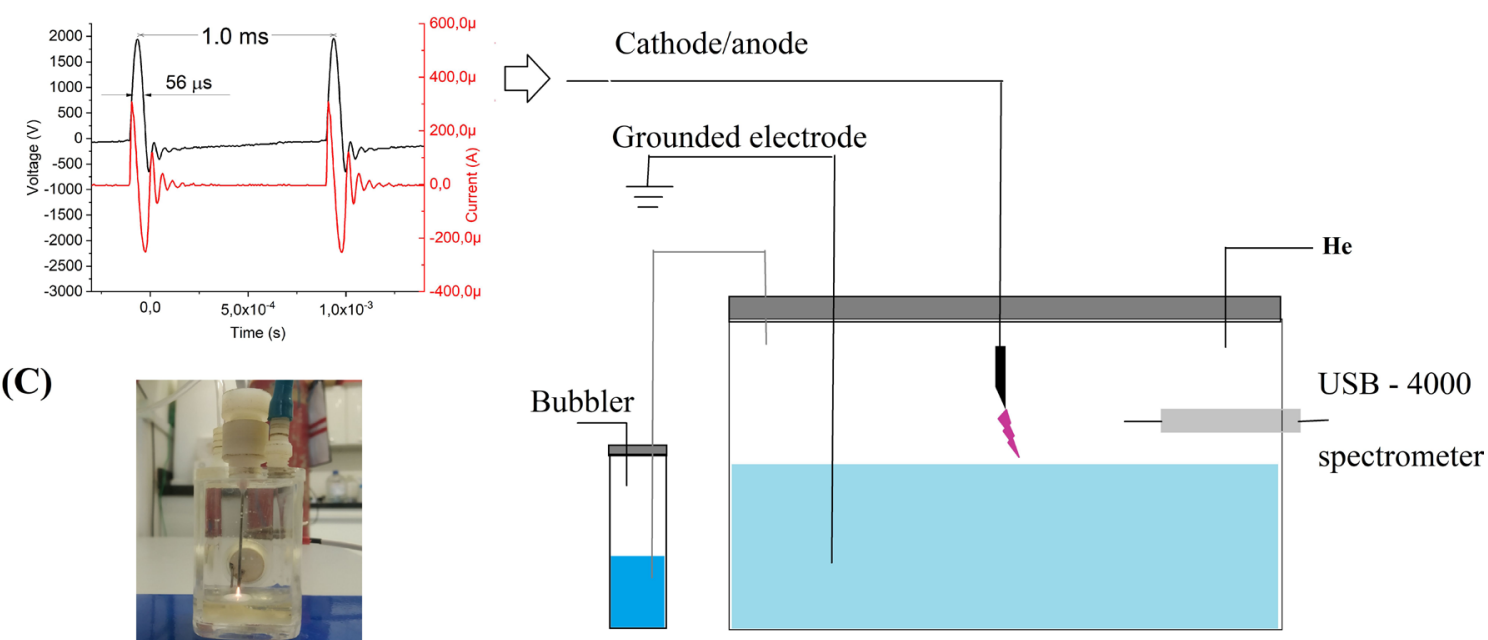

(C)

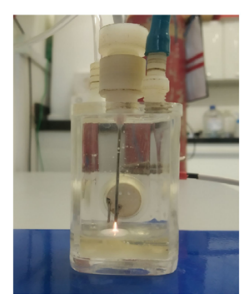

Grounded electrode

Figure 1. (A) The measured current and voltage time dependence of the discharge; (B) Experimental apparatus used in this work showing detail of reactor and bubbler; (C) Reactor during plasma treatment. 
for each process. The atomic emission from plasma was recorded kinetically with a gate width of $500 \mathrm{~ms}$ during a total cumulative period of $10 \mathrm{~s}$ for individual measurement . After treatment, $\mathrm{pH}$ measurements and chemical analysis in HSW and bubbler water were performed. To make sure that residual nitrogen from air was not present in the carrier gas, nitrate and nitrite species was analyzed by quantofix strips purchased from Sigma Aldrich. X-ray diffraction was used to determine the crystal structures of the salt crystals formed on HSW surface during the discharge.

\section{Results and Discussion}

\subsection{Plasma diagnostic}

During the treatment (anodic or cathodic) an intermittent discharge changed colors from pink (Figure 2A) to yellow (Figure 2C). This flashing is possibly due a phenomenon called poisoning, in which the electrical resistance of the electrode is changed by the deposited salt film from solution species. In fact, after application of the discharge a film of precipitated crystals on the solution surface was observed for cathodic polarization (Figure 2D).

On the other hand, in the anodic polarization only a turbidity of the solution was observed, caused by fine crystals dispersed. This result shows that film crystals formation was more intense in the cathodic configuration than in the anodic configuration. Before starting the OES process monitoring, we performed OES in the wide range of 200 to $800 \mathrm{~nm}$ to see which emissive species can be detected in both anodic and cathodic polarizations (Figure 3 ). A series of atomic He emission lines (e.g. 388, 501, 587, 667, $706 \mathrm{~nm}$ ) is observed, because He was used as atmosphere for generating atmospheric plasma $^{31}$. Furthermore, OH (A2 $\Sigma+\rightarrow$ X2П around $309 \mathrm{~nm}), \mathrm{H} \beta(4 \mathrm{~d} \rightarrow 2 \mathrm{p}$ at $486 \mathrm{~nm})$ and $\mathrm{H} \alpha(3 \mathrm{~d} \rightarrow$ $2 \mathrm{p}$ at $656 \mathrm{~nm}$ ) emission lines also are observed. A series of peaks observed at $315,337,353,357,375$, and $380 \mathrm{~nm}$ corresponds to the emission of second positive-system band (SPB; $\mathrm{C} 3 \Pi \rightarrow$ В3П) of $\mathrm{N}_{2}$. Due to the low peak intensities obtained for $\mathrm{N}_{2}$, it can be concluded that the air leakage is negligible.

Regarding the intensity of optical emission of $\mathrm{OH}$ (309 nm), which is the strongest peak for both the cathodic and anodic configuration, that can be mainly through following the reactions of plasma containing $\mathrm{H}_{2} \mathrm{O}$ vapor with helium gas $^{32}$ :

$$
\begin{aligned}
& \mathrm{H}_{2} \mathrm{O}+e^{-} \rightarrow \mathrm{H}+\mathrm{OH}+e^{-} \\
& \mathrm{He}^{+}+\mathrm{H}_{2} \mathrm{O} \rightarrow \mathrm{He}+\mathrm{H}_{2} \mathrm{O}^{+} \\
& \mathrm{H}_{2} \mathrm{O}^{+}+\mathrm{H}_{2} \mathrm{O} \rightarrow \mathrm{H}_{3} \mathrm{O}^{+}+\mathrm{OH}
\end{aligned}
$$

Strong emissions from $\mathrm{OH}(309 \mathrm{~nm})$ and $\mathrm{H}(656 \mathrm{~nm})$ implies that the gas contains water vapors. Since water vapor are diluted in helium atmosphere, we can compare the plasma species in relation to the intensity of $\mathrm{He}(587 \mathrm{~nm})$. Comparing the intensity of $\mathrm{He}(587 \mathrm{~nm})$ and $\mathrm{OH}(309 \mathrm{~nm})$ peaks, $\left(\mathrm{I}_{\mathrm{OH}} / \mathrm{I}_{\mathrm{He}}\right)$, for different moments during process, using a total cumulative period of $10 \mathrm{~s}$ for individual measurement, we found an average value of $2.44 \pm 0.06$ and $5.88 \pm 0.02$ for cathode and anode configurations, respectively. In other words, the $\mathrm{OH}$ emission more than doubled when was changed to the anode polarization. Data from literature ${ }^{33}$ suggest that for anode configuration, there is a large cathode voltage fall at
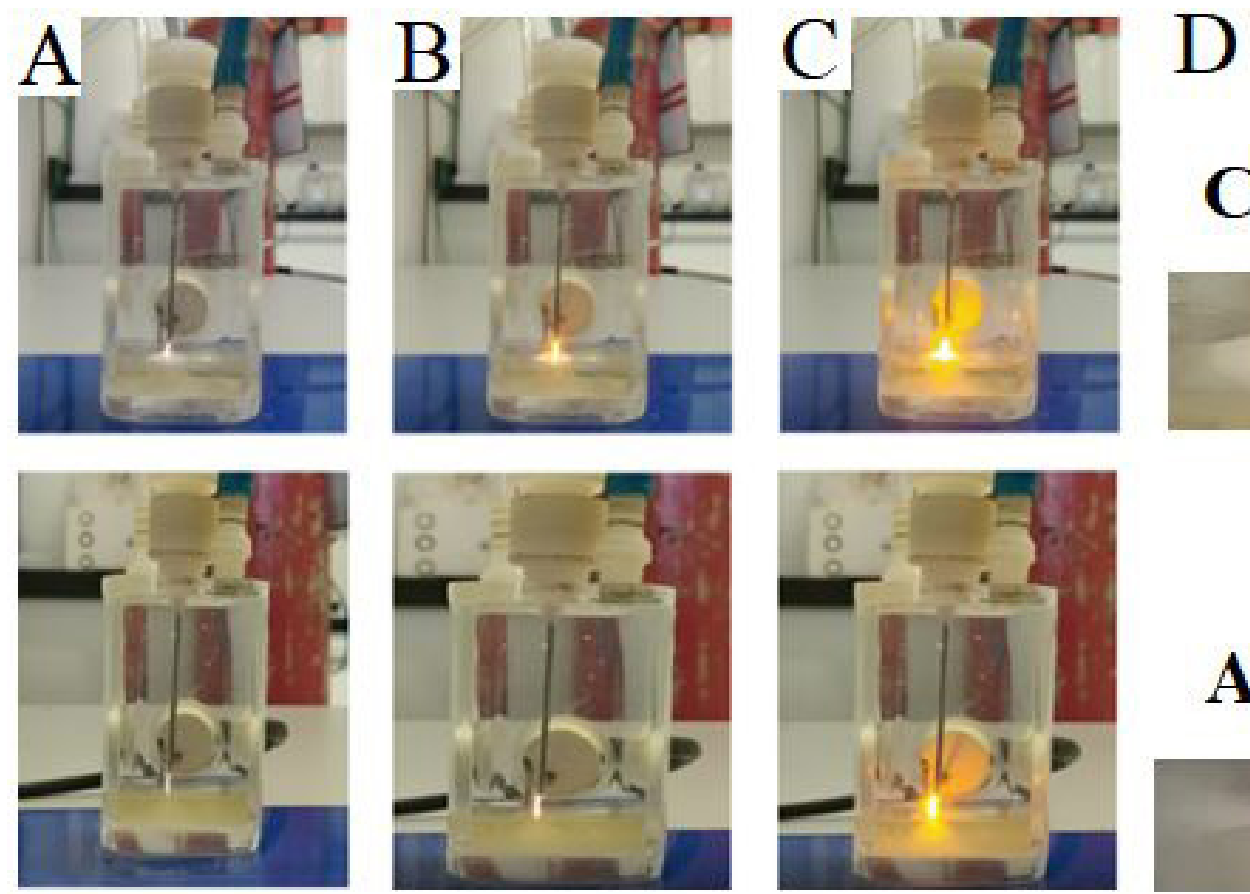

\section{Cathode}

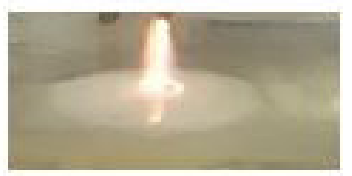

\section{Anode}

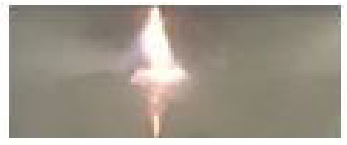

Figure 2. Different instants during plasma treatment. In the first moment plasma present pink color (A) and then starting to flicker (B), changing to yellow color (C). Details of crystal film formed in cathodic and turbidity in anodic configurations (D). 
the plasma-liquid interface. The He ions in the bulk plasma will then be driven by this voltage fall to move toward the liquid surface creating secondary effects, by interacting with the constituents of the liquid in the plasma-liquid interface, triggering charge transfer reactions, as well as transferring material from the liquid to the plasma phase. On the other hand, electric field in the plasma phase induces ionic charges in the cathode liquid to form a bridge cone-like shape (Taylor cones) on the free surface, leading to the emission of small, charged droplets, in this case traveling from the liquid surface towards the anode (plasma electrode) $)^{34}$. These droplets can provide water molecules to the bulk plasma, in this form of non-equilibrium evaporation that does not need the gas phase to be saturated with water to occur. The $\mathrm{H}_{2} \mathrm{O}$ transferring to the plasma leads to further $\mathrm{OH}$ production (Equations 1-3) and reduction of the metal ions in the droplets (Equation 4).

$M^{n+}+n e^{-}=M^{0}$

On the other hand, in cathode polarization, there is no voltage fall at the plasma-liquid interface, but a low energy electron shower onto the liquid surface, dissolving into the liquid to form hydrated electrons, which have a strong reducing ability, being able to produce $\mathrm{OH}^{26}$. However, since $\mathrm{OH}$ is short-lived, the chances of this species generated on the surface of the liquid surviving during the path to the core of plasma (where the OES probe was pointed), are drastically decreased. Thus, the emission of $\mathrm{OH}$, compared to He can be justified assuming that reaction 1-3 occur mostly on water transferred from the solution to the bulk plasma. These result corroborate with the findings in previous studies that have demonstrated that the dominant plasma emissions changed from $\mathrm{N}_{2}$ in the pure Ar plasma jet to $\mathrm{OH}$ when water vapor was added in the atmosphere ${ }^{35}$. Other elements such as $\mathrm{Mg}$ (285 nm), $\mathrm{Na}(589.5 \mathrm{~nm})$ and $\mathrm{Cl}(725.6 \mathrm{~nm})$, which were originally on the liquid as solvated ions, can be observed in the OES spectrum. To estimate the temporal variation of this element concentrations in the plasma, the intensity ratio $\mathrm{I} / \mathrm{I}_{\mathrm{He}(587)}$ was used (Figure 4). One interesting finding of this spectrum is the strong intensity ratio of $\mathrm{Na}(589.5 \mathrm{~nm})$ in the anodic configuration. This fact partially corroborates the hypothesis of ${ }^{36}$, in which the production mechanism of these species is closely related to the droplets produced by local evaporation, containing solvated ions, mostly $\mathrm{Na}^{+}$. Then, the aqueous sodium ions turn into a gas phase with rapid dehydration; the neutral sodium atoms remain and are excited to the upper states of the D-line transitions by electron impact in the plasma state ${ }^{36}$. However, this mechanism is not satisfied when trying to apply the case of the greater intensity of the $\mathrm{Mg}, \mathrm{Cl}$ and $\mathrm{K}$ lines observed in the cathode configuration. In the anodic configuration, due to the highest intensity of the $\mathrm{OH}$ line $(309 \mathrm{~nm})$, there is a greater number of droplets with solvated ions than in the cathode configuration. Therefore, it was expected that the intensity ratio of the other solutes would also be higher in the anodic. When the discharge is applied using a cathode configuration, the water surface is deformed by the cathode's electric attraction and a meniscus, such as the Taylor cone, is formed. This cone grows until it reaches the electrode, keeping the discharge inside the formed cone. Particles can be seen inside the cone and near the discharge, which were later identified as $\mathrm{NaCl}$ crystals. Thus, we postulate that $\mathrm{Na}(589.5 \mathrm{~nm})$ emission line decreased compared to anode configuration due this crystallization.

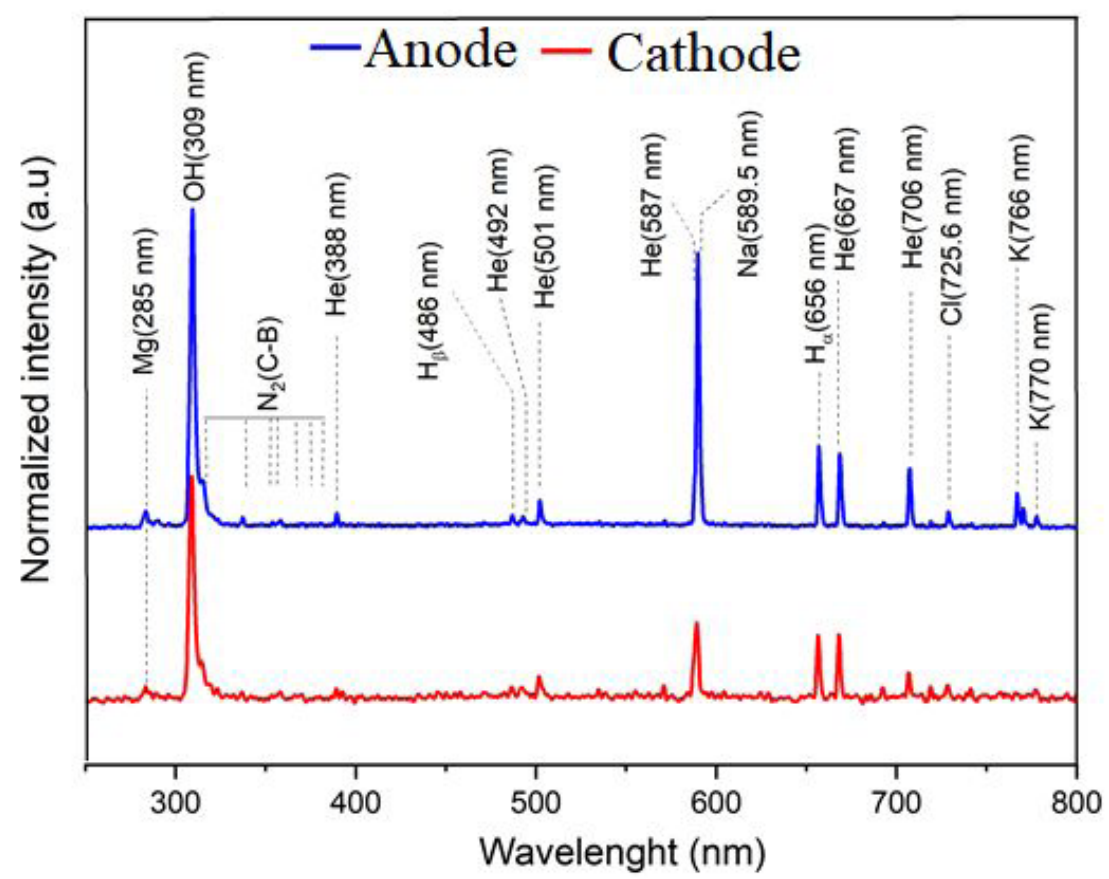

Figure 3. Optical emission spectroscopy (OES) in the wide range of 200 to $800 \mathrm{~nm}$, after $600 \mathrm{~s}$ of discharge on HSW solution surface for anodic or cathodic configuration. 

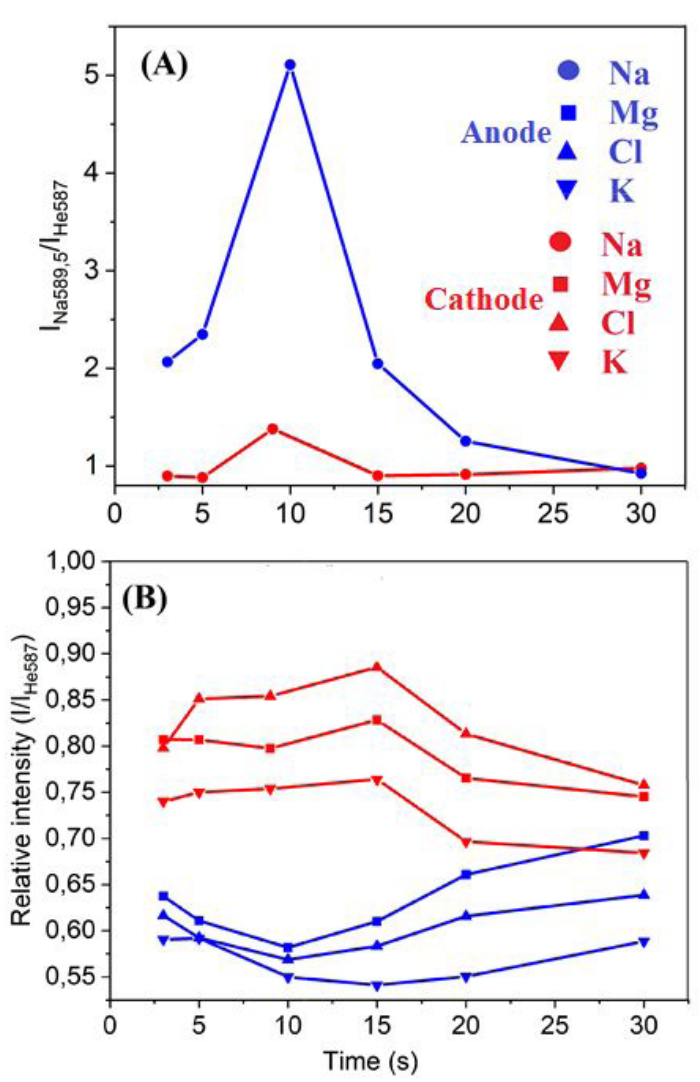

Figure 4. Evolution of intensity ratios $\left(\mathrm{I} / \mathrm{I}_{\mathrm{He}(587)}\right.$ of the OES peak spectra, at different moments, using a total cumulative period of 10 $\mathrm{s}$ for individual measurement from both anode plasma and cathode plasma for (A) $\mathrm{Na}$; and (B) $\mathrm{Mg}, \mathrm{Cl}$ and $\mathrm{K}$.

\subsection{Solutions analysis}

After plasma treatment both solutions resulted in lower $\mathrm{pH}$ (Figure 5). The acidity of the solution in cathode plasma is higher than anode plasma. It is usually suggested in the literature that acidification by plasma exposure is caused by generation of nitrogen-containing acid species as $\mathrm{HNO}_{2}$ and $\mathrm{HNO}_{3}$ in the liquid. In this work, as showed previously (Figure 3), the presence of nitrogen is due only to the air leakage in the vessel. Thus, the greater acidification of the solution in cathodic polarization must be explained using a different scenario. Exposure of cathode or anode plasma to an electrolyte solution is often accompanied by an increase in the concentration of $\mathrm{H}^{+}$, that is, acidification. Such effect occurs through water ionization by helium ions (Equation 2) or high-energy electrons (Equation 5), both provided by the plasma, resulting in the production of $\mathrm{H}_{3} \mathrm{O}^{+}$(Equation 3), ultimately acidifying the solution without the participation of nitrogen-containing species $^{37}$ :

$\mathrm{H}_{2} \mathrm{O}+e^{-} \rightarrow \mathrm{H}_{2} \mathrm{O}^{+}+2 e^{-}$

As this process is cyclical (Equations 2 and 5), the concentration of $\mathrm{H}_{3} \mathrm{O}^{+}$(Equation 3) in the solution will be increased if the plasma is in contact with the liquid, however, this effect is often not relevant enough to the $\mathrm{pH}$ of the bulk liquid and is more widely considered to occur locally because

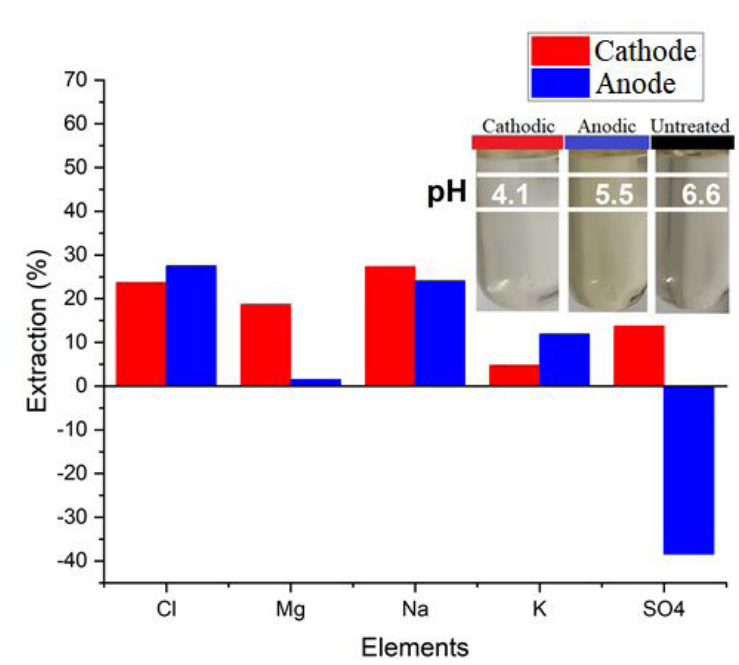

Figure 5. Extraction efficiency of $\mathrm{Na}, \mathrm{Mg}, \mathrm{Cl}, \mathrm{SO} 4$ and $\mathrm{K}$ from HSW solution after plasma treatment and $\mathrm{pH}$ values (above) of the cathode, anode and untreated solutions.

most approaches use large amounts of liquid. In small volumes such as $4.20 \mathrm{ml}$, where the volume of the plasma is not negligible compared to the volume of the liquid, the greater availability of electrons of the cathodic configuration leads to a greater acidification of the solution, which does not necessarily mean due to species containing nitrogen.

The extraction efficiency of solute from solvent was determined by comparing the mass fractions of chemical elements after $\left(\mathrm{C}_{\mathrm{f}}\right)$ and before $\left(\mathrm{C}_{\mathrm{i}}\right)$ plasma treatment (Equation 6):

$\%$ Extration $=\frac{C_{i}-C_{f}}{C_{i}}$

From this data (Figure 5), we can see that the concentration of $\mathrm{SO}_{4}$ was increased after anode plasma treatment. $\mathrm{HSW}$ treated by anode plasma resulted in the highest extraction of solutes, except for Mg. One explanation for this apparent contradiction lies in the sequence of salt precipitation during thermal evaporation experiments of seawater. From previous studies, it is known that $\mathrm{MgSO} 4$ is the last compound to precipitate $^{38}$. Thus, a possible explanation for this result is to assume that, in anodic plasma, evaporation by local heating was the predominant effect. This hypothesis was reinforced when we observed that in the solution treated bu anode plasma there was greater evaporation than in the cathode treatment It was found that the final volume in the anodic configuration was $3.76 \mathrm{ml}$ against $4.15 \mathrm{ml}$ in the cathode configuration, that is, loss of $11(\% \mathrm{v} / \mathrm{v})$ and $2.5(\%$ $\mathrm{v} / \mathrm{v}$ ), respectively.

In addition to local heating, another possible mechanism that occurs during plasma-activated precipitation can be attributed to the alignment of the dipoles in the solvation layer towards the opposites, in order to facilitate the breaking of the solvation shell and consequent precipitation ${ }^{12,34}$. When $\mathrm{NaCl}$ (for example) is dissolved in water, the $\mathrm{Na}+$ and $\mathrm{Cl}^{-}$ ions are hydrated by the polar water molecules, forming double-layer structure with opposite signs of charges ${ }^{10}$. 
For distilled water, the water bridge formed by the cone Taylor, between water surface and electrode, contains water with internal shell containing $\mathrm{H}+$ ions, while the outer shell contains more $\mathrm{OH}^{-}$ions ${ }^{19}$. With the assistance of the electric field, the ion and polar water molecules move to the opposite directions so that the positive and negative charge centers are not coincident with each other, which produces an electric dipole moment in the aqueous solution ${ }^{34}$ If the electric field is influencing crystallization, there may be selective extraction, especially considering ionic charges. In fact, looking at the behavior of $\mathrm{Mg}^{2+}$ and $\mathrm{SO}_{4}^{2-}$, which are pairs of strongly dipolar ions, it appears that there was selective extraction in the cathode plasma ${ }^{39}$.

Now looking at the $\mathrm{pH}$ change in the distilled water contained in the bubbler (Table 2), it can be observed that there was a significant decrease in $\mathrm{pH}$, as well as presence of chlorine ion $\mathrm{Cl}^{-}$, both are explained by the hydrolysis of chlorine gas that is generated by the reaction of $\mathrm{Cl}^{-}$with $\mathrm{OH}$ radicals (and potentially other oxidative ions/radicals) in the plasma phase and in the plasma-liquid interface ${ }^{40}$ :

$$
\begin{aligned}
& \mathrm{OH}^{*}+\mathrm{Cl}-\rightarrow \mathrm{Cl}+e^{-} \\
& \mathrm{Cl}+\mathrm{Cl} \rightarrow \mathrm{Cl}_{2}
\end{aligned}
$$

Table 2. Mass concentration and $\mathrm{pH}$ of the bubbler water before and after plasma treatment.

\begin{tabular}{cccc}
\hline & Destilled water & Cathode & Anode \\
\hline $\mathrm{pH}$ & 7.3 & 3.8 & 4.1 \\
\hline $\mathrm{Cl}^{-}\left(\mathrm{mgL}^{-1}\right)$ & - & 46.1 & 42.5 \\
\hline
\end{tabular}

and subsequently, the hydrolysis in the liquid trap:

$\mathrm{Cl}_{2}+\mathrm{H}_{2} \mathrm{O} \rightarrow 2 \mathrm{H}^{+}+\mathrm{Cl}^{-}+\mathrm{ClO}^{-}$

$\mathrm{Na}^{+}$and $\mathrm{Mg}^{2+}$ ions as well as nitrate and nitrite were not observed in the bubbler solution, meaning that salt particles do not travel in gas phase to the liquid trap and instead remain in the reaction chamber.

\subsection{Precipitate analysis}

After the solutions were filtered, the crystals retained in the filter were analyzed by X-ray diffraction (Figure 6). In the solution treated in cathode plasma, before filtration, particles of precipitates deposited on the internal surface of the reactor, as well as on the surface of the stainless electrode, were scraped off, for separate XRD analysis. Comparing phase of crystals formed on surface from anode and cathode configurations, there is a predominance of the Halite $(\mathrm{NaCl})$ phase in the salt crystals precipitated on HSW surface treated by cathode plasma, different from the solution treated by anode plasma, which presented significant amounts of other phases, mainly the Bischofite $\left(\mathrm{MgCl}_{2}\right.$. $6 \mathrm{H}_{2} \mathrm{O}$ ). The most surprising result to emerge from these data is with respect to the greater purity of the salts treated in the cathodic configuration. The opposite was expected to happen, since there was greater extraction of the solutes of $\mathrm{Mg}, \mathrm{K}, \mathrm{Cl}$ and $\mathrm{SO} 4$ in the solution treated with cathodic plasma for (Figure 5). This apparent inconsistency can be answered by looking at the XRD of the scraped off salts (Figure 6) that were condensed on the reactor walls and on the stainless-steel electrode. Compounds with different

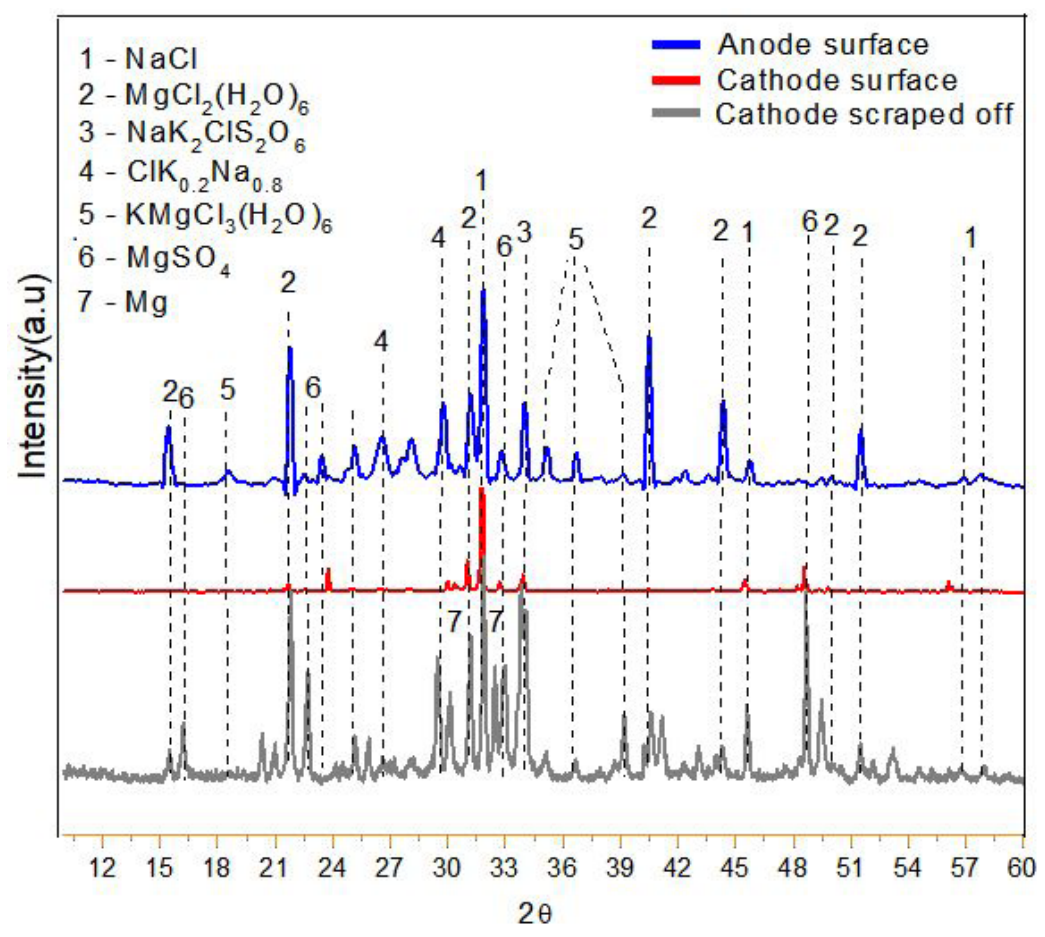

Figure 6. X-Ray Diffractions of filtrated crystals from anode (blue), cathode (red) solutions and solids deposited in the reactor wall and electrode in cathodic configuration (black). 
hydration states, such as MgSO4 and double salts, indicate different precipitation rates which are constrained by solution composition, environmental conditions. It was also observed other intense peaks, present only in the scraped material, which was characterized as (201) and (100) planes of the bulk-metallic magnesium with hexagonal structure. Thus, salt is either formed at the interface between plasma and liquid or in the plasma phase, by the evaporation or dissociation of the water in those droplets leaving solute ions that then stabilize in the solid form. In the case of the crystals formed from the droplets, they are the result of completely drying single droplets and therefore, will crystallize salts having its composition reflecting that of the droplet. This makes possible to crystallize other salts that have solubility higher and do not precipitate in the solution, or at least does not remain in solid state while in the solution. These particles that were scraped off are, thus, mostly composed of salt crystallized surrounded by the energetic plasma media from droplets with complex composition, reflecting the composition of the surface of the solution in the moment of the droplet formation, this ultimately leads to a mixture of many salts, and the presence of double salts with other ions present in the brine. The precipitation kinetics of salts on the HSW surface are dependent on polarization. While in anodic polarization different compounds are formed, in cathodic polarization preferentially $\mathrm{NaCl}$ is formed. According to ICDD (International Centre for Diffraction Data) standards, considering the ICDD card 01-072-1668, diffraction peak for halite can be observed at $27.4^{\circ}, 31.7^{\circ}, 45.4^{\circ}, 53.7^{\circ}$ and $56.4^{\circ}$ and relative intensities of $8.8 \%, 100 \%, 61 \%, 2.2 \%$ e $18.2 \%$, for planes (111), (200), (220), (311) e (222), respectively. However, mainly for precipitates produced in a solution treated with cathodic plasma, a strong intensity increases of the (220) Bragg peaks were observed.

This increase evidence the significant development of the dodecahedron $\left\{\begin{array}{lll}1 & 1 & 0\end{array}\right\}$ faces occurred. Alkaline halide crystals (e.g., $\mathrm{NaCl}, \mathrm{KCl}, \mathrm{KBr}, \mathrm{KI}$ ) tend to modify their growth morphologies either due to a change in evaporation rate resulting in a high supersaturation, or to the presence of additives ${ }^{41}$ and the media in plasma should favor those changes.

As for the cathodic plasma, unlike anodic, precipitation will proceed by the already discussed water vapor/droplet formation. This is true because when cathode pulsed corona discharge is applied over conductive solutions, an avalanche of electrons is driven towards water, producing vapour bubbles ${ }^{12,42}$. As mentioned before, the salts formed that remained in solution are similar for to the anodic ones, differing by the fact that in the anodic configuration more magnesium salts are obtained.

Further studies are still required to better understand this mechanism and how this can be used to separate different ions from the solution, but we can already correlate the polarity of the plasma with the type of mechanism for salt extraction and the composition of the resulting salt. For example, for cathodic configurations, if the electric field is high enough, we can expect salt to be extracted from the solution with less water evaporation, since it is more efficient on pulling salt forming cations, given the polarity of the plasma. By attracting the metallic cations for the outermost layer of the water, the salt formation outside the solution is more considerable because the only stable form for these components to exist out of solution is in solid form, this polarity, in our system, drags more solute from the solution and crystallizes them in the form of a mix of salts outside the solution, while precipitating mostly $\mathrm{NaCl}$ in liquid phase, once other ions are removed.

In the case of anodic plasma, only anions are in the surface closer to the plasma, with the high availability of $\mathrm{Cl}^{-}$that are oxidized by plasma radicals and leave the system in the form of $\mathrm{Cl}_{2}$. Because of the bombardment of the liquid surface with positive ions, and the cathode fall close to the liquid, salt particles are not created or ejected towards the electrode or the reactor walls, however, since Magnesium is not extracted, the salt remaining in solution is not mainly $\mathrm{NaCl}$ anymore, leading to a mix between $\mathrm{NaCl}$ and $\mathrm{Mg}$-containing salts, which ultimately creates a comprehensible way of how plasma-liquid systems can be used to separate salts from solution.

\section{Conclusion}

In this study, pulsed corona discharge (PCD) was generated to produce plasma over hypersaline water (HSW). The interaction mechanism is dependent on the discharge polarization. In cathode polarization considerable amount of solute to HSW surface occurs, and metallic cations can be extracted from the solution in the form of salts deposited in solid surfaces in the vicinities of the plasma. This deposited salt is a complex mixture of the brine solute counterparts, but the extraction of such ions allows a higher purity salt (mostly $\mathrm{NaCl}$ ) to be precipitated in the solution. In anodic configuration no salt is deposited outside the solution and the solute ions remain in the liquid phase. Since the other cations are not extracted, this gives crystals that have sodium chloride as main solid but with the presence of $\mathrm{MgCl}_{2} \cdot 4\left(\mathrm{H}_{2} \mathrm{O}\right)$ and $\mathrm{MgSO}_{4}$. For both configurations, $\mathrm{Cl}^{-}$ions are extracted in the form of $\mathrm{Cl}_{2}$. We thus believe that this work can serve as a starting point on the comprehension of how plasma can be used for desalination processes and lead to further development of the field of interactions of saline aqueous solutions and plasma discharges. In the cathodic polarization, a crystal film with high $\mathrm{NaCl}$ purity is formed around the discharge application point. Also on the reactor walls and on the stainless steel electrode (cathode), saline films were deposited, typically composed of $\mathrm{NaCl}, \mathrm{MgCl} 2$ and $\mathrm{MgSO} 4$ with different hydration states, in addition to double salts and metallic Mg. In anodic polarization, crystals are formed only on the surface of the HSW. They are dispersed crystals, composed of salts of $\mathrm{NaCl}, \mathrm{MgCl} 2, \mathrm{MgSO} 4$ and double salts. Two mechanisms of crystallization are being proposed, by evaporation and by breaking the solvation layer. Evaporation occurs either by ohmic heating of the conductive bridge formed between the cathode and the HSW (Taylor cone) or by injection of droplets into the plasma due to ion bombardment (anodic polarization). The breakdown of the solvation layer occurs by alignment of the dipoles in the solvation layer towards the opposites

\section{Acknowledgment}

This project was funded by the National Council for Scientific and Technological Development (CNPQ430863/2016-0), the National Institute of Surface Engineering (CNPq-465423/2014-0), and the National Council for the Improvement of Higher Education (CAPES). 


\section{References}

1. Davies PA, Knowles PR. Seawater bitterns as a source of liquid desiccant for use in solar-cooled greenhouses. Desalination. 2006;196(1-3):266-79.

2. Darvishmanesh S, Pethica BA, Sundaresan S. Forward osmosis using draw solutions manifesting liquid-liquid phase separation. Desalination. 2017;421:23-31.

3. Loganathan P, Naidu G, Vigneswaran S. Mining valuable minerals from seawater: a critical review. Environ Sci Water Res Technol. 2017;3(1):37-53. http://dx.doi.org/10.1039/ C6EW00268D.

4. Chung TS, Zhang S, Wang KY, Su J, Ling MM. Forward osmosis processes: yesterday, today and tomorrow. Desalination. 2012;287:78-81. http://dx.doi.org/10.1016/j.desal.2010.12.019.

5. Cath TY, Childress AE, Elimelech M. Forward osmosis: principles, applications, and recent developments. J Membr Sci. 2006;281(1-2):70-87

6. Shahmansouri A, Min J, Jin L, Bellona C. Feasibility of extracting valuable minerals from desalination concentrate: A comprehensive literature review. J Clean Prod. 2015;100:4-16. http://dx.doi.org/10.1016/j.jclepro.2015.03.031.

7. Bardi U. Extracting minerals from seawater: an energy analysis. Sustainability. 2010;2(4):980-92.

8. Gabrić B, Sander A, Cvjetko Bubalo M, Macut D. Extraction of S- and N-compounds from the mixture of hydrocarbons by ionic liquids as selective solvents. ScientificWorldJournal. 2013;2013:512953.

9. Mutaz ISAI, Wagialia KM. Production of magnesium from desalination. Resour Conserv Recycling. 1990;3:231-9.

10. Sellner B, Valiev M, Kathmann SM. Charge and electric field fluctuations in aqueous $\mathrm{NaCl}$ electrolytes. J Phys Chem B. 2013;117(37):10869-82.

11. Dubinov AE, Lyubimtseva VA. crystallization features of aqueous solutions in their droplets evaporated by nanosecond spark discharge treatment. High Energy Chem. 2019;53(1):3-6.

12. Almada LFA, Fontes KES, Vitoriano JO, Melo VRM, Fraga FEN, Alves-Junior C. Applying pulsed corona discharge in hypersaline droplets. J Phys D Appl Phys. 2021;54(5):055202.

13. Bartzis V, Sarris IE. A theoretical model for salt ion drift due to electric field suitable to seawater desalination. Desalination. 2020;473:114163. http://dx.doi.org/10.1016/j.desal.2019.114163.

14. Mariotti D, Belmonte T, Benedikt J, Velusamy T, Jain G, Švrček V. Low-temperature atmospheric pressure plasma processes for "Green" third generation photovoltaics. Plasma Process Polym. 2016;13(1):70-90.

15. Bruggeman PJ, Kushner MJ, Locke BR, Gardeniers JGE, Graham WG, Graves DB, et al. Plasma-liquid interactions: a review and roadmap. Plasma Sources Sci Technol. 2016;25(5):053002.

16. Chiang WH, Mariotti D, Sankaran RM, Eden JG, Ostrikov K. Microplasmas for advanced materials and devices. Adv Mater. 2020;32(18):1-23

17. Ekanayake UGM, Seo DH, Faershteyn K, O'Mullane AP, Shon $\mathrm{H}$, MacLeod J, et al. Atmospheric-pressure plasma seawater desalination: clean energy, agriculture, and resource recovery nexus for a blue planet. Sustain Mater Technol. 2020;25:e00181. http://dx.doi.org/10.1016/j.susmat.2020.e00181.

18. Liu DX, Liu ZC, Chen C, Yang AJ, Li D, Rong MZ, et al. Aqueous reactive species induced by a surface air discharge: heterogeneous mass transfer and liquid chemistry pathways. Sci Rep. 2016;6(apr):1-11.

19. Graves DB. Low temperature plasma biomedicine: a tutorial review. Phys Plasmas. 2014;21(8):080901-1-13.

20. Jiang B, Zheng J, Qiu S, Wu M, Zhang Q, Yan Z, et al. Review on electrical discharge plasma technology for wastewater remediation. Chem Eng J. 2014;236:348-68. http://dx.doi. org/10.1016/j.cej.2013.09.090.
21. Ramli NAH, Zaaba SK, Mustaffa MT, Zakaria A, Shahriman AB. Review on the development of plasma discharge in liquid solution. AIP Conf Proc. 2017;1824:030015.

22. Neretti G, Taglioli M, Colonna G, Borghi CA. Characterization of a dielectric barrier discharge in contact with liquid and producing a plasma activated water. Plasma Sources Sci Technol. 2017;26(1):0150131-15.

23. Gorbanev Y, O’Connell D, Chechik V. Non-thermal plasma in contact with water: the origin of species. Chemistry. 2016;22(10):3496-505

24. Rezaei F, Vanraes P, Nikiforov A, Morent R, De Geyter N. Applications of plasma-liquid systems : a review. Materials (Basel). 2019;12(2751):1-69.

25. Hamdan A, Cha MS. Ignition modes of nanosecond discharge with bubbles in distilled water. J Phys D Appl Phys. 2015;48(40):405206. http://dx.doi.org/10.1088/0022-3727/48/40/405206.

26. Rumbach P, Bartels DM, Sankaran RM, Go DB. The solvation of electrons by an atmospheric-pressure plasma. Nat Commun. 2015;6:1-6.

27. Schaper L, Graham WG, Stalder KR. Vapour layer formation by electrical discharges through electrically conducting liquids - Modelling and experiment. Plasma Sources Sci Technol. 2011;20(3):034003

28. Schaper L, Stalder KR, Graham WG. Plasma production in electrically conducting liquids. Plasma Sources Sci Technol. 2011;20(3):034004

29. Graham WG, Stalder KR. Plasmas in saline solution. J Phys Conf Ser. 2007;71(1):4-8.

30. Lavelle K. An Overview of Water and Wastewater Treatment. In: Cheremisinoff NP, editor Handbook of water and wastewater treatment technology. Boston: Butterworth-Heinemann; 1995. vol. 6: Applied Catalysis B: Environmental.

31. Himeno Y, Ogura Y, Shirafuji T. Time-resolved optical emission spectroscopy on three-dimensionally integrated micro solution plasma in He/H2O mixture. J Phys Conf Ser. 2014;518(1):012021.

32. Zhao YY, Wang T, Wilson MP, MacGregor SJ, Timoshkin IV, Ren QC. Hydroxyl Radicals and Hydrogen Peroxide Formation at Nonthermal Plasma-Water Interface. IEEE Trans Plasma Sci. 2016;44(10):2084-91.

33. Chen Q, Li J, Li Y. A review of plasma-liquid interactions for nanomaterial synthesis. J Phys D Appl Phys. 2015;48(42):424005.

34. Vanraes P, Bogaerts A. Plasma physics of liquids: a focused review. Appl Phys Rev. 2018;5(3):031103-1-56.

35. Srivastava N, Wang C. Effects of water addition on $\mathrm{OH}$ radical generation and plasma properties in an atmospheric argon microwave plasma jet. J Appl Phys. 2011;110(5):053304.

36. Kang WS, Hur M, Song YH. Effect of voltage polarity on the plasma-liquid interactions. Appl Phys Lett. 2015;107(9):1-5.

37. Wright KC, Kim HS, Cho DJ, Rabinovich A, Fridman A, Cho YI. New fouling prevention method using a plasma gliding arc for produced water treatment. Desalination. 2014;345(2-3):64-71.

38. Babel M, Schreiber BC. Geochemistry of evaporites and evolution of seawater. In: Mackenzie FT, editor. Treatise on geochemistry. 2nd ed. USA: Elsevier Science \& Technology; 2014. vol. 9, p. 483-560.

39. Gregson FKA, Robinson JF, Miles REH, Royall CP, Reid JP. Drying kinetics of salt solution droplets: water evaporation rates and crystallization. J Phys Chem B. 2019;123(1):266-76.

40. Wang X, Zhou M, Jin X. Application of glow discharge plasma for wastewater treatment. Electrochim Acta. 2012;83:501-12. http://dx.doi.org/10.1016/j.electacta.2012.06.131.

41. Rodriguez-Navarro C, Linares-Fernandez L, Doehne E, Sebastian E. Effects of ferrocyanide ions on $\mathrm{NaCl}$ crystallization in porous stone. J Cryst Growth. 2002;243(3-4):503-16.

42. Huang Y, Yan H, Wang B, Zhang X, Liu Z, Yan K. The electroacoustic transition process of pulsed corona discharge in conductive water. J Phys D Appl Phys. 2014;47(25):255204. 